\title{
Modification of the postural pattern of the trunk by means of a set of shoe lifts
}

\author{
Michele Romano ${ }^{1 *}$, Kjell Roger Heitmann², Alessandra Negrini', Matteo Mastrantonio ${ }^{1}$, Fabio Zaina', \\ Stefano Negrini ${ }^{3}$ \\ From 11th International Conference on Conservative Management of Spinal Deformities - SOSORT 2014 \\ Annual Meeting \\ Wiesbaden, Germany. 8-10 May 2014
}

\section{Background}

After the medical evaluation of a spinal disease, the indication of a shoe lift (SL) is prescribed in case of a recognized improvement of some specific outcome.

\section{Aim}

The purpose of this study is to measure sagittal and coronal imbalance of the trunk and modification of the hump magnitude, in standing position, in response to the use of a SL (for this study a series of SLs).

\section{Design}

Observational study.

\section{Methods}

We evaluated 35 consecutive female patients visited in ISICO Institute for spine diseases (scoliosis or hyperkyphosis). With the patient in a standing position, we carried out a set of tests performed with a three-dimensional rastereography (DIERS Formetric) with different SLs (5mm, $10 \mathrm{~mm}, 15 \mathrm{~mm}$.) placed alternatively under both feet. We assessed the variations of these different postural outcomes: modification of the hump, sagittal and coronal imbalance of the trunk.

\section{Results}

The statistical analysis of the seven acquisitions shows that:

- In the coronal plane, the average variation of the inclination of the line between $\mathrm{C} 7$ and the center of the sacrum is $1.8 \mathrm{~mm} \pm 0.32$.

${ }^{1}$ ISICO - Italian Scientific Spine Institute, Milan, Italy

Full list of author information is available at the end of the article
- In the sagittal plane the average variation of the inclination of the line between $\mathrm{C} 7$ and the center of the sacrum is $1.2 \pm 0.44$.

- In the horizontal plane the average variation of the main hump is statistically significantly different (reduction of average $3.1^{\circ} \pm 1.7$ ) when the SL is placed under the opposite foot (left hump - right foot).

\section{Conclusion}

A previous study focused on the observation of postural changes of the trunk in response to the use of a series of SLs demonstrated that the trunk does not change the specific postural characteristics.

This study that completes that previous evaluation, shows that the use of SLs alternatively placed under both feet does not show a statistical significative difference of the typical postural pattern of the trunk in coronal and sagittal plane. In the horizontal plane the use of a SL can reduce the hump magnitude.

\section{Authors' details}

${ }^{1} I S I C O$ - Italian Scientific Spine Institute, Milan, Italy. ${ }^{2}$ DIERS International $\mathrm{GmbH}$, Schlangenbad, Germany. ${ }^{3}$ University of Brescia - IRCCS Don Gnocchi, Brescia, Italy.

\section{Published: 4 December 2014}

\section{References}

1. Raczkowski JW, Daniszewska B, Zolynski K: Functional scoliosis caused by leg length discrepancy. Arch Med Sci 2010, 6(3):393-8.

2. Zabjek KF, Leroux MA, Coillard C, Martinez X, Griffet J, Simard G, Rivard CH: Acute postural 3. adaptations induced by a shoe lift in idiopathic scoliosis patients. Eur Spine J 2001, 10(2):107-13.

doi:10.1186/1748-7161-9-S1-03

Cite this article as: Romano et al:: Modification of the postural pattern of the trunk by means of a set of shoe lifts. Scoliosis 2014 9(Suppl 1):03. 